\author{
2021, Volume 8, ID 487 \\ Perspectives \\ DOI: $10.15342 /$ ijms.2021.487
}

\title{
Psychological Support and Telehealth Options for Patients with Cancer during the Covid-19 Pandemic in Saudi Arabia
}

\author{
Manal Banaser a (iD), Sami Alshammary ${ }^{b}$ (iD \\ a Nursing Affairs General Department, MOH Agency for Therapeutic Services, Ministry of Health, \\ Riyadh, Saudi Arabia. \\ ${ }^{\mathrm{b}}$ Palliative Medicine Consultant, King Fahd Medical City Rór, Riyadh, Saudi Arabia.
}

\begin{abstract}
Background: COVID-19 concerns are associated with an increase in symptoms of depression and anxiety among cancer patients. Telehealth services hold incredible potential for providing psychological support to cancer patients. In a technology-assisted intervention for telehealth, hotline services are a valuable tool to provide psychosocial care. This paper examines the use of hotline services to offer psychological support to cancer patients.

Methods: A retrospective analysis of hotline calls patient registry data was conducted. Data were collected from a single cancer center in Riyadh, from May 2020 to March 2021, with a random sample of 877 callers to cancer hotline services. Responses of a satisfaction questionnaire were linked to call-related concerns of registry data.

Results: A total of 877 calls were received, the majority of which came from Riyadh locals. Patient disease complaints accounted for 210 calls (24\%), while retake medicine requests accounted for 251 calls (28.62\%). 143 (16.31\%) calls were about scheduled new appointments, 261 calls $(29.76 \%)$ were about psychological issues induced by Covid-19, such as worry, fear, and anxiety symptoms, and 12 calls (1.37\%) having to do with Covid19. Seven hundred seventy-two callers $(88 \%)$ indicated satisfaction with the services call attended.

Discussion: Hotline services in cancer care have been identified as a key resource telehealth service that positively influences patient satisfaction and meets cancer patient needs in the face of the pandemic. This study also highlighted the need for other telehealth services, such as mental health mobile applications, virtual multidisciplinary care, and online support groups, which can provide an excellent option for providing psychological support to cancer patients.

Conclusion: This study found that providing Cancer Care Hotline services during a pandemic improves patient-centered care and a more efficient healthcare delivery system.
\end{abstract}

Keywords: Telehealth, Cancer Care, Covid-19 Pandemic, Psychological Support, Patient Centered Care, Hotline Services, Mental Health Apps, Saudi Arabia

Received: 18 Mar 2021; Revised: 12 Aug 2021; Accepted: 27 Aug 2021; Published: 08 Sept 2021

Correspondence: Manal Banaser, Nursing Affairs General Department, Ministry of Health, Riyadh, Saudi Arabia. Email: $\underline{\text { mbanaser@moh.gov.sa; mino_21652@yahoo.com }}$

Cite this article as: Banaser M, Alshammary S. The Psychological Support and Telehealth Services Opportunities for Patients with Cancer during the Covid-19 Pandemic in Saudi Arabia. Integr J Med Sci. 2021;8:487. [https://doi.org/10.15342/ijms.2021.487].

Copyright (C) 2021 Manal Banaser et al. This is an open access article distributed under the Creative Commons Attribution 4.0 International License, which permits unrestricted use, distribution, and reproduction in any medium, provided the original work is properly cited. 
INTRODUCTION

The rising coronavirus pandemic of 2019 (COVID-19) not solely presents a significant danger to our population's physical health but will also have adverse long-run effects on the mental state if we tend to refuse to reply now. Although social distancing is a vital tool to slow down the Pandemic's devastating consequences, it can lead to alienation, reduced physical activity, and increased rumination, which may affect people with pre-existing mental illness in particular [1]. In comparison, the flood of disheartening COVID-19 news offers food for intensified worry and distress, which can be harmful to people with chronic diseases such as patients with cancer [2,3].

A cancer diagnosis is devastating. COVID-19 exacerbates mental health issues, social and physical isolation, and difficulty accessing treatments and essential services [4]. Cancer patients across the globe become more anxious and attempting to cope with social isolation orders. They require tremendous support than any time before as medical appointments and procedures are canceled or postponed. Globally, studies indicate a rise in symptoms of depression and anxiety among cancer patients correlated with COVID-19 concerns [5-8]. In response to the Pandemic, many healthcare facilities have changed their spectrum of services to Telehealth to handle challenging healthcare services. Addressing the use of Telehealth is a tremendous promise to provide psychological support to cancer patients [9]. Research indicated that Telehealth is especially important for cancer patients, as patients will benefit from having intervention at home at all times, not necessarily during Pandemic [10]. Telehealth services around the globe were introduced a decade ago. Studies have shown that virtual visits do not compromise the quality of care and are as effective as in-person visits for delivering palliative care [9,11]. Hotline services as part of technology-assisted interventions will be vital for providing psychosocial care, promoting a patient-centered approach if best practice is followed [12].

In the light of the Pandemic, globally, cancer care facilities faced enormous challenges and increasing demands toward providing healthcare services to patients. Saudi Arabia, like many countries, faces the ultimate challenge to sustain and maintain a healthcare system within the imposed pandemic isolation and restrictions guidelines. There are currently 23 governmental centers providing cancer care across Saudi Arabia, and these services are offered free for citizens without costs [22]. Clinical practice guidelines from the national cancer center in Saudi were issued by March 2020 [23]. Numerous steps have been made concerning non-urgent on-site cancer treatment. Physicians were encouraged to collaborate virtually for multidisciplinary team sessions, while regular hospital follow-up appointments and non-urgent surgery were delayed or supplemented by virtual clinics [24]. A virtual network has provided support services for cancer patients, and drive-through or mail delivery has been used to deliver cancer patient's treatment [6,23]. A national register of COVID-19 for cancer patients has recently been developed to support similar COVID-19 cancer studies [23]. They are supporting the demand for more studies on cancer patients' needs after the Pandemic.

In Saudi Arabia, Telehealth is not newly introduced. As part of health transformation vision 2030, the health ministry adopted the digital health transformation to match the global health system development and expand health services through Telehealth [37]. In addition, telemedicine regulations and updated practice guidelines were issued by the national health information center in Saudi health Council [NHIC, SHC 2018]. Currently, 31 national referral hospitals and medical centers in $\mathrm{MOH}$ benefit from outreach clinical electronic services across the kingdom $[21,38]$.

Saudi Arabia tended to demonstrate the firm basis for the use of Telehealth during a pandemic [38,39]. The Ministry of Health $(\mathrm{MOH})$ in Saudi Arabia has recently added new functionality to the existing Telehealth systems that have been successfully implemented into the provision of healthcare using smartphone apps (e.g., Seha, Mawid, Tawakklna, Thibaud, and Tetamman) to cope with the Pandemic [40]. Research into the user experience found that 50 percent of consumers were happy with these new TH smartphone app providers [38]. This was a powerful enabler, suggesting that the Saudi health care infrastructure was sufficiently prepared to deal with outbreaks such as COVID-19 [40]. Thus, showing the public's digital literacy was not an enormous barrier.

In the Saudi context of cancer care, digital cancer clinics were launched during the COVID19 Pandemic in Tele Medicine in Cancer Care [41]. However, cancer patients face specific difficulties, such as loss of physical interaction and psychological pressure, including depression, anxiety, and tension during virtual treatment, due to the complexities of cancer care [20]. Indeed, the absence of virtual psychological resources for cancer patients will place further difficulties and medical anxiety on health care providers. During these difficult 
moments, the maintenance of therapeutic care is also equally vital for the progression of recovery and patient outcomes.

Studies have shown that mental health care shortcomings during the Covid-19 Pandemic can be resolved through teleconferencing software for therapy sessions.

Indeed, studies emphasized telemedicine use can empower patient-centered care compared to non-digital therapeutic sessions [42].

In light of the COVID-19 pandemic, a hotline is an invaluable telehealth service. People with low digital literacy who are unaware of online communication through apps or other online platform services should benefit from the hotline service and those who do not have access to internet-based services. Many countries indicated that online mental health services could not replace crisis hotlines [46]. These hotline services are the only available infrastructure in some geographical locations. Further, many people still have limited access to Internet-based information or assistance, do not know how to use the applicants, or even do not have a smartphone [46]. The research recommended that country collaboration is essential and that seeking guidance from global mental health experts is equally important to intervene in public mental health issues during a pandemic [47] — Saudi Arabia among the countries that initiated hotline services extensively to provide psychological support for the public. For example, the Saudi health ministry announces COVID-19 disaster hotline services through specific extensions (ext-937) that are reachable to all public 24-hours on-call seven-day services [37]. The Saudi Arabian National, Critical Care Society, released practice guidelines for managing critical care patients and recommendations for psychological support, guiding healthcare professionals to incorporate psychological support systems for patients and providing psychological services for individuals in need [48]. This paper investigates using technology-assisted intervention, including hotline services, to provide psychological support to cancer patients during the pandemic. It provides an overview of hotline services to address the psychological health concerns of cancer patients in Saudi Arabia.

\section{METHODS}

Design

A retrospective study on patient registry data of hotline services and reported form results Setting

Cancer regional referral center in Riyadh, Saudi Arabia

Participants

Participants are a random sample of 877 callers to cancer hotline services from May 2020 to March 2021. This observational retrospective study investigated hotline call services launched in May 2020 in Riyadh's single cancer regional referral center. The regional cancer center recruited four volunteers callers (nurses, clerks) urgently in response to people's psychological needs during the COVID-19 pandemic.

Data collection

Data was collected from two data sources. The patient satisfaction questionnaire and internal patient hotline call registration. The Patient hotline data registration include data on the number of calls and reason for calls, or patient concerns is listed into four areas:

1. Patient disease complaints.

2. Retake medication requests.

3. Related to book a new appointment.

4. Psychological problems related to Covid-19 including worry, fear, and anxiety symptoms.

The patient satisfaction questionnaire includes one question asked to those callers who contact cancer hotline services. The question is: 'are you overall satisfied with the contact you had with hotline cancer services? The callers answered this question on 4 Likert scale categories: very satisfied, satisfied, less satisfied, and not satisfied. Responses of a satisfaction questionnaire were linked to call-related concerns data. This made to investigate the impact of pandemic pressure on rising patient needs and mental health concerns of the cancer patient.

\section{STATISTICAL ANALYSIS}

Information reported from callers to cancer hotline services was recorded by four volunteers recruited from the center (nurses, clerks) on a standard form after assuring confidentiality and informing patients that calls will be recorded for improvement. Callers' concerns are grouped into four areas:

1. Patient disease complaints. 
2. Retake medication requests.

3. Related to booking the new appointment.

4. Psychological problems related to Covid-19 including worry, fear, and anxiety symptoms.

Descriptive statistics, including frequency and percentage, identified the number of calls received from patients and caregivers and related reasons. Patient concerns were reported by month. The satisfaction level of callers was classified into two categories (satisfied and dissatisfied) for the purpose of descriptive analysis as very satisfied and satisfied to 'satisfied category' and less satisfied and not satisfied to 'dissatisfied category.'

\section{RESULTS}

A total of 877 telephone calls were answered From May 10, 2020, to March 17, 2021, mostly from patients and caregivers. There were 12 missing calls reported. The number of calls and the reason for calls frequency and percentage are presented in Table 1. The patient concerns reported by month are shown in Figure 1-the satisfaction level reported by callers whether patient or caregivers were described Figure 2.

\begin{tabular}{|c|c|}
\hline \multicolumn{2}{|l|}{ Number of calls attended: 877 calls } \\
\hline Problem resolved during call & $\%$ of total received call \\
\hline Partially resolved & $11.17 \%$ \\
\hline No not resolved & $3.53 \%$ \\
\hline Yes resolved & $85.29 \%$ \\
\hline Reasons for calls & $\%$ of total received call \\
\hline Got new appointment & $16.42 \%$ \\
\hline $\begin{array}{l}\text { Other (Psychological: worry- fear, anxiety } \\
\text { symptom }\end{array}$ & $29.76 \%$ \\
\hline Medication retake request & $29.42 \%$ \\
\hline Patient Complaint & $24.40 \%$ \\
\hline Satisfaction of call attended & $\%$ of total received call \\
\hline Very Satisfied & $89.40 \%$ \\
\hline Satisfied & $9.01 \%$ \\
\hline Not satisfied & $0.23 \%$ \\
\hline Less satisfied & $1.37 \%$ \\
\hline The relationship of caller to patient & $\%$ of total received call \\
\hline Daughter/Son & $52.45 \%$ \\
\hline Others & $10.83 \%$ \\
\hline Sister / Brother & $4.79 \%$ \\
\hline Patient himself & $27.94 \%$ \\
\hline Mother/Father/ Parents & $3.99 \%$ \\
\hline
\end{tabular}

A total of 877 calls were answered From May 10, 2020, to March 17, 2021, mostly from residents in Riyadh and surrounded areas. 210 calls (24\%) about patient disease complaints and 251 calls were $(28.62 \%)$ related to retake medication requests, 143 (16.31\%) calls were related to booked new appointments, and 261 calls $(29.76 \%)$ were psychological problems caused by Covid-19 including worry, fear and anxiety symptoms, and, 12 calls $(1.37 \%)$ had no response. (See Table 1$)$.

The patient concerns reported by month are shown in Figure 1.

Out of the 877 calls, 453(51.65\%) calls were attended by patient daughter or son, 245 $(27.94 \%)$ calls were followed by patients themselves, $42(4.79 \%)$ calls were received from patient sister or brother, 35 (3.99\%) calls were attended by the patient's mother or father, and $90(10.26 \%)$ calls were attended by others (friends, relatives).

In terms of satisfaction with call attended. 772 calls $(88.03 \%)$ reported satisfaction with the services to call treated. 79 calls $9.01 \%$ were partially satisfied with attended calls-the satisfaction level reported by callers, whether patient or caregivers, was described in Figures 2 and 3.

These data indicated that using hotline services significantly impacts support services and can promote psychological support for cancer patients during the pandemic. 


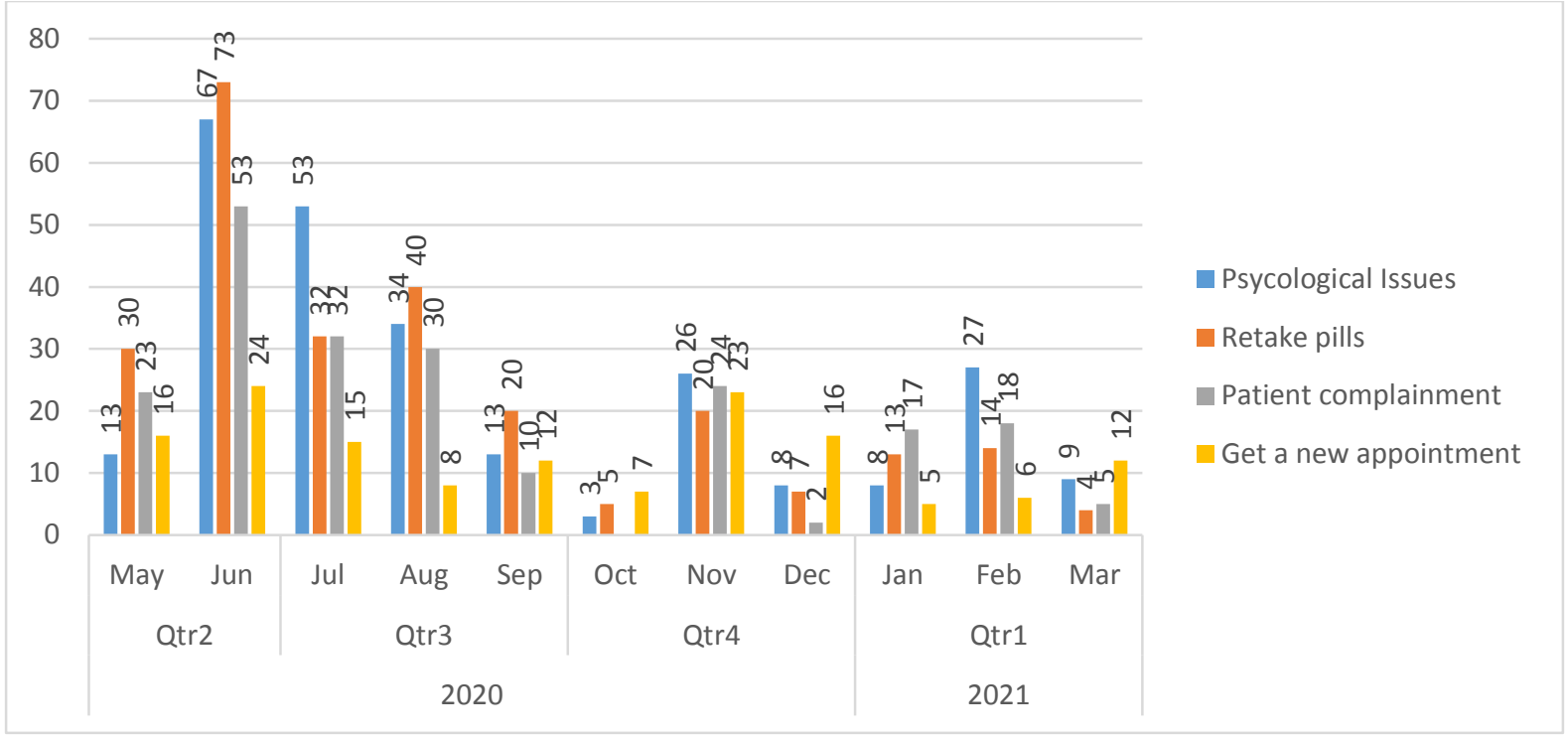

Figure 1: Patient concerns reported by Month

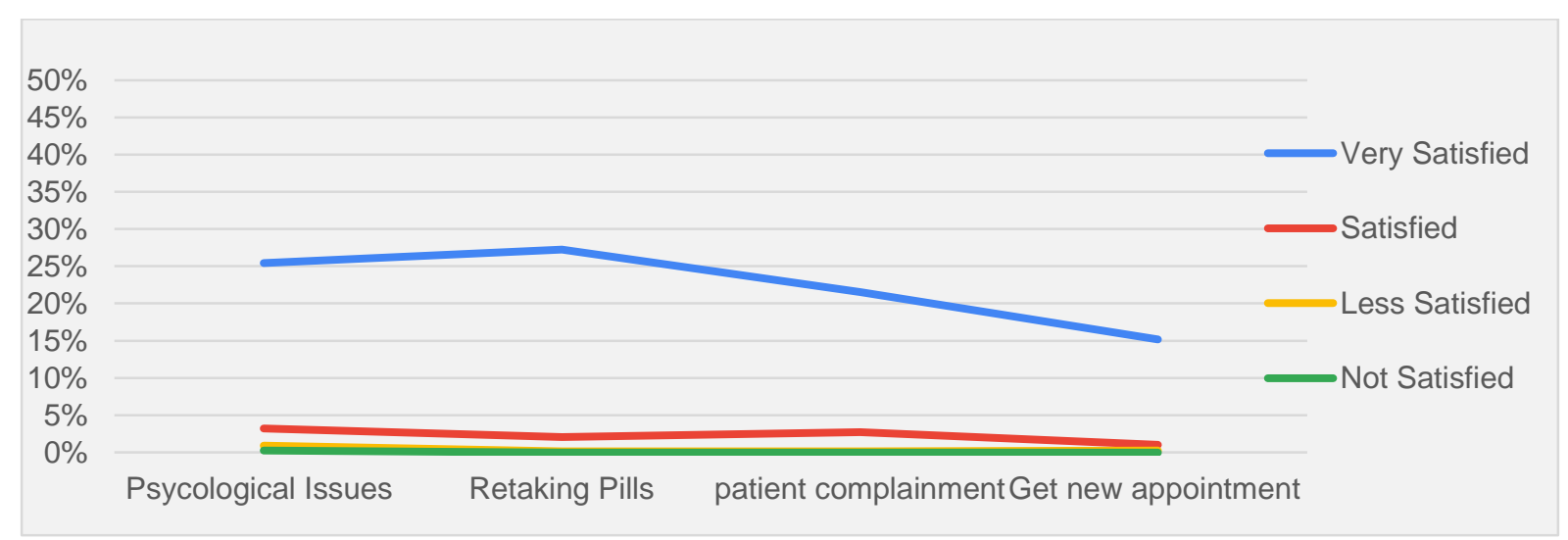

Figure 2: General Satisfaction level with hotline services calls

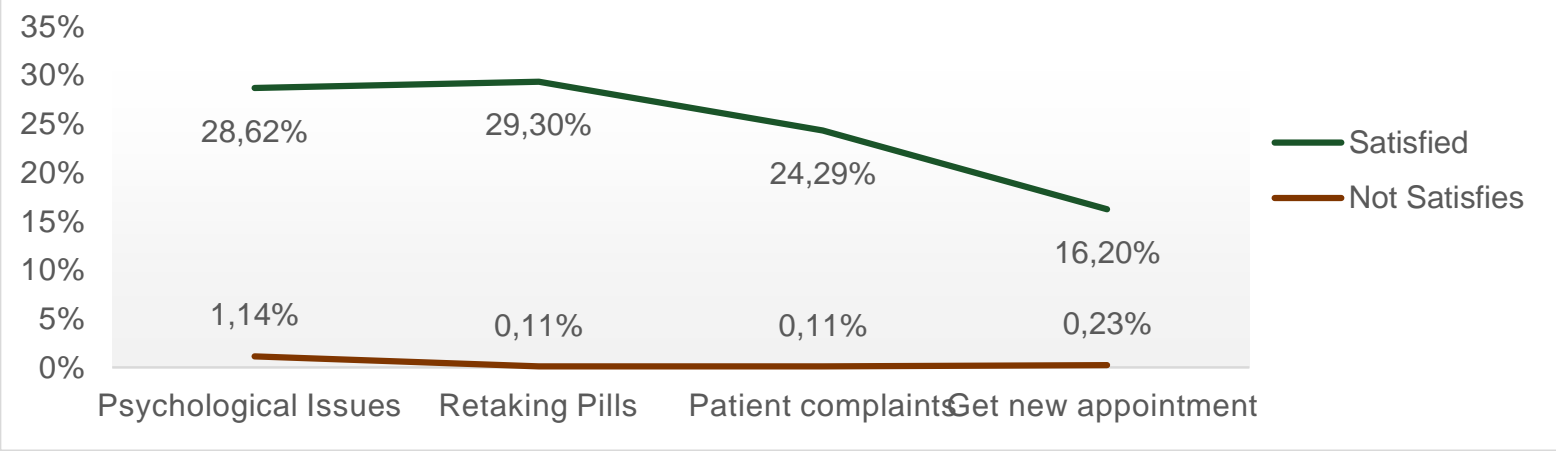

Figure 3: Sum of satisfaction level with hotline call services

\section{DISCUSSION}

This paper investigates using technology-assisted intervention, including hotline services, to provide psychological support to cancer patients during the Pandemic. According to this study, hotline services in cancer care have been identified as a critical resource telehealth service that influences patient satisfaction and satisfies cancer patient needs in the face of the Pandemic. 
Patients with Cancer are especially vulnerable during this Pandemic and already suffer from high isolation levels [7,63]. This is closely associated with increased symptoms of depression and anxiety [3], physical morbidity, and mortality [28]. The previous study indicates that cancer patients are interested in using technologies to improve their mental health and that mobile health technology is practical and effective for measuring cognitive and mental disease [25].

Telehealth, including virtual psychological support, will also retain the kind of empathy vital for encouraging patient-centered care (Junaid et al. 2020). Empathy plays an integral part in the relationship between health providers and patients. Empathic interaction includes a patient submitting socio-emotional signals to share an affective state, a practitioner to sense and communicate empathy, and a patient to experience that empathy [64].

However, video consultations may induce filtering effects that inhibit the interpretation of these socio-emotional signals, which means that compassion cannot be seen or not be perceived [43]. To increase the efficiency of telecommunications, clinicians understanding should be expressed by matching the patient's expression style, displaying body language associated with the patient's practical situation, keeping eye contact and active stance, presenting encouraging comments, and posing open questions are essential to maintain effective communication $[42,65]$. Furthermore, the healthcare system should ensure that the requisite infrastructure is in place to provide secure digital interventions that do not compromise personal privacy and reduce the risk of data breaches [66]. Apps and text messaging must be efficient and discreet, protected, and responsible; in the same way, clinicians are held to ethical standards of responsible practice and confidentiality [67].On the other hand, there are also enormous difficulties to the use of Telehealth in cancer care. Specifically, in Middle Eastern countries, research has shown that sociocultural factors are still obstacles to overcome when considering Telehealth [68]. Vulnerable Patients who are typically older and illiterate may lack the knowledge to link to video consultation.

In contrast, patients from low-income households may lack the financial resources to do so [58]. On a more promising side, Telehealth helps patients to access adequate treatment from a distance. They had to drive long distances to get to specialist clinics and pay a high premium for customized treatments in the past, which affected care and recovery and the quality of life [10]. Telehealth decreases exhausting travel, gradually improving their mental health.

With COVID-19 and the transition to Telehealth, clinicians may have more flexibility to genuinely listen to patients, offer comprehensive information, and include them in the decision-making process since they may not have to commute between treatment centers. These notions of a patient-centered approach have been shown to increase survival rates [10]. It also gives a more holistic approach, which involves psychological and emotional support $[42,69]$.

As a result, hotline services appear to be widely accepted by patients. The Hotline services can be applied to other cancer care settings in various contexts, such as expanding hotline calls services to include more referrals to cancer support services such as social care, psychiatry, and spiritual care. Additionally, the number of staff working on hotlines benefits should be increased to cover more than just working hour's shifts. Furthermore, more research is needed to compare results to those of other cancer centers, which is critical and to follow up on the effect of these services on patient well-being and the quality of care they receive.

While using hotline services can cover most target patient groups because it does not necessitate complex internet-based services or digital literacy on the part of the patient. Research also highlighted other telehealth opportunities, such as mental health mobile applications, virtual multidisciplinary care, and online support groups, which provide an excellent option for providing psychological support to cancer patients.

\section{CONCLUSION}

This paper explored the value of telehealth services, including hotline services, as part of a technology-assisted intervention to support cancer patients' psychological well-being during the Covid-19 Pandemic in Saudi Arabia. This study found that providing Cancer Care Hotline services during a pandemic improves patient-centered care and a more efficient healthcare delivery system. However, advancements in its coverage and modality may make it more patient-friendly and affordable. The integration of hotline services with tele oncology may become a new standard of care in the coming years.

There is a need for further studies on digital psychological assistance during the COVID-19 Pandemic. The technology-assisted psychological intervention has a significant effect on patients, particularly in those with Cancer. Further investigation into its impact on the 
psychological status of cancer patients is required. Lessons learned during this Pandemic will enable us to face the challenges of this and future pandemics, particularly about addressing a patient-centered approach to people in the local context of the Saudi health system and other international healthcare settings with Cancer through Telehealth.

\section{Acknowledgments}

The authors would like to thank the main regional cancer center directors for facilitating data collection for this research.

\section{Authors' contributions}

The participation of each author corresponds to the criteria of authorship and contributorship emphasized in the Recommendations for the Conduct, Reporting, Editing, and Publication of Scholarly work in Medical Journals of the International Committee of Medical Journal Editors. Indeed, all the authors have actively participated in the redaction, the revision of the manuscript, and provided approval for this final revised version.

Funding

No funding was received from any organization to conduct the present study.

Conflict of interest

The authors declare that there is no conflict of interest regarding the publication of this article.

Ethical approval

We obtained ethical approval from the main regional cancer center in Riyadh, IRB Log No. 21-294E.

\section{REFERENCES}

[1] Xiang YT, Yang Y, Li W, Zhang L, Zhang Q, Cheung T, et al. Timely mental health care for the 2019 novel coronavirus outbreak is urgently needed. Lancet Psychiatry. 2020 Mar;7(3):228-29.

Doi: 10.1016/s2215-0366(20)30046-8

[2] Wang Y, Duan Z, Ma Z, Mao Y, Li X, Wilson A, et al. Epidemiology of mental health problems among patients with cancer during COVID-19 pandemic. Transl Psychiatry. 2020 Jul 31;10(1):263.

Doi: 10.1038/s41398-020-00950-y

[3] Ng KYY, Zhou S, Tan SH, Ishak NDB, Goh ZZS, Chua ZY, et al. Understanding the Psychological Impact of COVID-19 Pandemic on Patients With Cancer, Their Caregivers, and Health Care Workers in Singapore. JCO Global Oncol. 2020 Oct;6: 1494-509.

Doi: $10.1200 /$ go.20.00374

[4] Al-Quteimat OM, Amer AM. The Impact of the COVID-19 Pandemic on Cancer Patients. Am J Clin Oncol. 2020 Jun; 43(6):452-55.

Doi: $10.1097 /$ coc.0000000000000712

[5] Liang W, Guan W, Chen R, Wang W, Li J, Xu K, et al. Cancer patients in SARS-CoV2 infection: a nationwide analysis in China. Lancet Oncol. 2020 Mar;21(3):335-37.

Doi: 10.1016/s1470-2045(20)30096-6

[6] Jazieh A-R, Al Hadab A, Al Olayan A, AlHejazi A, Al Safi F, Al Qarni A, et al. Managing oncology services during a major coronavirus outbreak: lessons from the Saudi Arabia experience. JCO Glob Oncol. 2020 Mar;6:518-24.

Doi: $10.1200 /$ go.20.00063

[7] Salako O, Okunade K, Allsop M, Habeebu M, Toye M, Oluyede G, et al. Upheaval in cancer care during the COVID-19 outbreak. Ecancermedicalscience. 2020 Apr $1 ; 14:$ ed97.

Doi: $10.3332 /$ ecancer.2020.ed97

[8] Tsamakis K, Triantafyllis AS, Tsiptsios D, Spartalis E, Mueller C, Tsamakis C, et al. COVID-19 related stress exacerbates common physical and mental pathologies and affects treatment (Review). Exp Ther Med. 2020 Jul;20(1):159-62.

Doi: $10.3892 /$ etm.2020.8671

[9] Schnur JB, Montgomery GH. E-counseling in psychosocial cancer care: a survey of practice, attitudes, and training among providers. Telemed J E Health. 2012 May;18(4):305-8. 
Doi: $10.1089 / \mathrm{tmj} .2011 .0142$

[10] Grewal US, Terauchi S, Beg MS. Telehealth and Palliative Care for Patients With Cancer: Implications of the COVID-19 Pandemic. JMIR Cancer. 2020 Nov 24;6(2):e20288.

Doi: $10.2196 / 20288$

[11] AlDossary S, Martin-Khan MG, Bradford NK, Smith AC. A systematic review of the methodologies used to evaluate telemedicine service initiatives in hospital facilities. Int J Med Inform. 2017 Jan;97:171-94.

Doi: $10.1016 /$ j.ijmedinf.2016.10.012

[12] Turvey C, Fortney J. The Use of Telemedicine and Mobile Technology to Promote Population Health and Population Management for Psychiatric Disorders. Curr Psychiatry Rep. 2017 Oct 16;19(11):88

Doi: $\underline{10.1007 / \mathrm{s} 11920-017-0844-0}$

[13] World Health Organization. Critical Preparedness, Readiness And Response Actions for COVID-19.WHO. 2021. [Accessed 2021 Aug 30]. Available from: https://www.who.int/publications/i/item/critical-preparedness-readiness-andresponse-actions-for-covid-19

[14] Organization WHO. WHO Covid-19 situation report 181.

[15] Qiu J, Shen B, Zhao M, Wang Z, Xie B, Xu Y. A nationwide survey of psychological distress among Chinese people in the COVID-19 epidemic: implications and policy recommendations. Gen Psychiatr. 2020 Mar 6;33(2):e100213.

Doi: 10.1136/gpsych-2020-100213

[16] Zakout YM, Alreshidi FS, Elsaid RM, Ahmed HG. The magnitude of COVID-19 related stress, anxiety and depression associated with intense mass media coverage in Saudi Arabia. AIMS Public Health. 2020 Sep 1; 7(3):664-678.

Doi: 10.3934/publichealth.2020052

[17] Mongkhon P, Ruengorn C, Awiphan R, Thavorn K, Hutton B, Wongpakaran N, et al. Exposure to COVID-19-Related Information and its Association With Mental Health Problems in Thailand: Nationwide, Cross-sectional Survey Study. J Med Internet Res. 2021 Feb 12; 23(2):e25363.

Doi: $10.2196 / 25363$

[18] Elhessewi GMS, Almoayad F, Mahboub S, Alhashem AM, Fiala L. Psychological distress and its risk factors during COVID-19 pandemic in Saudi Arabia: a crosssectional study. Middle East Current Psy. 2021;28(1):7.

Doi: 10.1186/s43045-021-00089-6

[19] 2020 M. CASES REPORT STATUS ; Ministery of Health. Secondary CASES REPORT STATUS ; Ministery of Health 2020. [Accessed 2021 Sep 1]. Available From: https://www.moh.gov.sa/en/CCC/events/covid-19/Pages/2020.aspx

[20] Prevention SSCfDCa. Saudi Center for Disease Control and Prevention (2020) Coronavirus Disease COVID-19 Guidelines, Saudi Center for Disease Control and Prevention (2020) COVID-19 interactive dashboard: daily-updates. Secondary Saudi Center for Disease Control and Prevention (2020) Coronavirus Disease COVID-19 Guidelines, Saudi Center for Disease Control and Prevention (2020) COVID-19 interactive dashboard: daily-updates 2020. [Accessed 2021 Sep 01]. Available from: https://covid19.cdc.gov.sa/daily-updates/

[21] Algaissi AA, Alharbi NK, Hassanain M, Hashem AM. Preparedness and response to COVID-19 in Saudi Arabia: Building on MERS experience. J Infect Public Health. 2020 Jun; 13(6):834-838.

Doi: 10.1016/j.jiph.2020.04.016

[22] Jazieh AR, Akbulut H, Curigliano G, Rogado A, Alsharm AA, Razis ED, et al. Impact of the COVID-19 Pandemic on Cancer Care: A Global Collaborative Study. JCO Glob Oncol. 2020 Sep;6:1428-38.

Doi: $10.1200 /$ go.20.00351

[23] Alessy SA, Davies EA, Jazieh AR. Cancer care during the COVID-19 pandemic: a perspective from Saudi Arabia. Ecancermedicalscience. 2020 Jul 17;14:1076.

Doi: 10.3332/ecancer.2020.1076

[24] Tashkandi E, Zeeneldin A, AlAbdulwahab A, Elemam O, Elsamany S, Jastaniah W, et al. Virtual Management of Patients With Cancer During the COVID-19 Pandemic: Web-Based Questionnaire Study. J Med Internet Res. 2020 Jun 24;22(6):e19691.

Doi: $10.2196 / 19691$

[25] Brar GA-OX, Pinheiro LA-O, Shusterman MA-O, Swed B, Reshetnyak E, Soroka O, et al. COVID-19 Severity and Outcomes in Patients With Cancer: A Matched Cohort Study. J Clin Oncol. 2020 Nov 20;38(33):3914-3924. 
Doi: $10.1200 /$ jco.20.01580

[26] Banik GR, Alqahtani AS, Booy R, Rashid H. Risk factors for severity and mortality in patients with MERS-CoV: Analysis of publicly available data from Saudi Arabia. Virol Sin. $2016 \mathrm{Feb} ; 31(1): 81-4$.

Doi: $10.1007 / \mathrm{s} 12250-015-3679-\mathrm{z}$

[27] Ofori-Asenso R, Ogundipe O, Agyeman AA, Chin KL, Mazidi M, Ademi Z, et al. Cancer is associated with severe disease in COVID-19 patients: a systematic review and meta-analysis. Ecancermedicalscience. 2020 May 18;14:1047.

Doi: 10.3332/ecancer.2020.1047

[28] Lee LY, Cazier JB, Angelis V, Arnold R, Bisht V, Campton NA, et al. COVID-19 mortality in patients with cancer on chemotherapy or other anticancer treatments: a prospective cohort study. Lancet. 2020 Jun 20;395(10241):1919-26.

Doi: $10.1016 / \mathrm{s} 0140-6736(20) 31173-9$

[29] Di Lorenzo G, Di Trolio R, Kozlakidis Z, Busto G, Ingenito C, Buonerba L, et al. COVID 19 therapies and anti-cancer drugs: A systematic review of recent literature. Crit Rev Oncol Hematol. 2020 Aug;152:102991.

Doi: $\underline{\text { 10.1016/j.critrevonc.2020.102991 }}$

[30] Boilève A, Stoclin A, Barlesi F, Varin F, Suria S, Rieutord A, et al. COVID-19 management in a cancer center: the ICU storm. Support Care Cancer. 2020 Oct;28(10):5037-5044.

Doi: $10.1007 / \mathrm{s} 00520-020-05658-9$

[31] Giannakoulis VG, Papoutsi E, Siempos II, . Effect of Cancer on Clinical Outcomes of Patients With COVID-19: A Meta-Analysis of Patient Data. JCO Glob Oncol. 2020 Jun;6:799-808.

Doi: $10.1200 / \mathrm{go} .20 .00225$

[32] Downar J, Seccareccia D. Palliating a pandemic: "all patients must be cared for". J Pain Symptom Manage. 2010 Feb;39(2):291-5.

Doi: 10.1016/j.jpainsymman.2009.11.241

[33] Chen G, Wu Q, Jiang H, Zhang H, Peng J, Hu J, et al. Fear of disease progression and psychological stress in cancer patients under the outbreak of COVID-19. Psychooncology. 2020 Sep;29(9):1395-98.

Doi: $10.1002 /$ pon. 5451

[34] Organization WH. Global diffusion of eHealth: making universal health coverage achievable: report of the third global survey on eHealth. 2017.[Accessed 2021 Sep 01]. Available from:

https://www.ghdonline.org/uploads/WHO_ReportGlobal_diffusion_of_eHealth_Maki ng universal health coverage achievable.pdf

[35] Sirintrapun SJ, Lopez AM. Telemedicine in Cancer Care. Am Soc Clin Oncol Educ Book. 2018 May 23;38:540-45.

Doi: $10.1200 /$ edbk 200141

[36] Huckvale K, Wang CJ, Majeed A, Car J. Digital health at fifteen: more human (more needed). BMC Med. 2019 Mar 18;17(1):62.

Doi: $10.1186 / \mathrm{s} 12916-019-1302-0$

[37] Hassounah M, Raheel H, Alhefzi M. Digital Response During the COVID-19 Pandemic in Saudi Arabia. J Med Internet Res. 2020 Sep 1;22(9):e19338-e38.

Doi: $\underline{10.2196 / 19338}$

[38] Alshahrani A, Stewart D, MacLure K. A systematic review of the adoption and acceptance of eHealth in Saudi Arabia: Views of multiple stakeholders. Int J Med Inform. 2019 Aug;128:7-17.

Doi: 10.1016/j.ijmedinf.2019.05.007

[39] Kaliyadan F, A Al Ameer M, Al Ameer A, Al Alwan Q. Telemedicine Practice in Saudi Arabia During the COVID-19 Pandemic. Cureus. 2020 Dec 9;12(12):e12004.

Doi: $10.7759 /$ cureus. 12004

[40] Alghamdi SM, Alqahtani JS, Aldhahir AM. Current status of telehealth in Saudi Arabia during COVID-19. J Family Community Med. 2020 Sep-Dec;27(3):208-211.

Doi: $10.4103 /$ jfcm.jfcm $295 \_20$

[41] Jazieh AR, Chan SL, Curigliano G, Dickson N, Eaton V, Garcia-Foncillas J, et al. Delivering Cancer Care During the COVID-19 Pandemic: Recommendations and Lessons Learned From ASCO Global Webinars. JCO Glob Oncol. 2020 Sep;6:146171.

Doi: $\underline{10.1200 / g 0.20 .00423}$ 
[42] Penedo FJ, Oswald LB, Kronenfeld JP, Garcia SF, Cella D, Yanez B. The increasing value of eHealth in the delivery of patient-centred cancer care. Lancet Oncol. 2020 May;21(5):e240-e51.

Doi: $10.1016 / \mathrm{s} 1470-2045(20) 30021-8$

[43] Terry C, Cain J. The Emerging Issue of Digital Empathy. Am J Pharm Educ. 2016 May 25;80(4):58.

Doi: 10.5688 /ajpe 80458

[44] Simpson S, Richardson L, Pietrabissa G, Castelnuovo G, Reid C. Videotherapy and therapeutic alliance in the age of COVID-19. Clin Psychol Psychother. 2021 Mar ;28(2) :409-421.

Doi: $10.1002 / \mathrm{cpp} .2521$

[45] Wozniak AM, Rallis KS, Elkaddoum R. Telemedicine health disparities in oncology care. Future Oncol. 2021 May; 17(14):1695-1698.

Doi: 10.2217/fon-2021-0022

[46] Ma R, Nguyen R, Oakman JM. Dissemination Strategies and Usage of Psychological Assistance Hotlines During the COVID-19 Outbreak in China. Fronti Commun. 2020 Jul 23;5:60

Doi: $10.3389 /$ fcomm.2020.00060

[47] Dong L, Bouey J. Public Mental Health Crisis during COVID-19 Pandemic, China. Emerg Infect Dis. 2020 Jul;26(7):1616-1618.

Doi: $10.3201 /$ eid2607.200407

[48] Alhazzani W, Al-Suwaidan F, Al Aseri Z, Al Mutair A, Alghamdi G, A Rabaan A, et al. The saudi critical care society clinical practice guidelines on the management of COVID-19 patients in the intensive care unit. Saudi Critical Care J. 2020;4(2):27-44.

Doi: $10.4103 /$ sccj.sccj_15_20

[49] Chambers SK, Ritterband LM, Thorndike F, Nielsen L, Aitken JF, Clutton S, et al. Web-Delivered Cognitive Behavioral Therapy for Distressed Cancer Patients: Randomized Controlled Trial. J Med Internet Res. 2018 Jan 31;20(1):e42.

Doi: $10.2196 /$ jmir. 8850

[50] Atallah N, Khalifa M, El Metwally A, Househ M. The prevalence and usage of mobile health applications among mental health patients in Saudi Arabia. Comput Methods Programs Biomed. 2018 Mar;156:163-168.

Doi: $10.1016 /$ j.cmpb.2017.12.002

[51] Heckel L, Fennell KM, Orellana L, Boltong A, Byrnes M, Livingston PM. A telephone outcall program to support caregivers of people diagnosed with cancer: utility, changes in levels of distress, and unmet needs. Support Care Cancer. 2018 Nov;26(11):378999.

Doi: $10.1007 / \mathrm{s} 00520-018-4246-6$

[52] Chow PI, Showalter SL, Gerber MS, Kennedy E, Brenin DR, Schroen AT ,et al. Use of Mental Health Apps by Breast Cancer Patients and Their Caregivers in the United States: Protocol for a Pilot Pre-Post Study. JMIR Res Protoc. 2019 Jan 14;8(1):e11452. Doi: $\underline{10.2196 / 11452}$

[53] Paterson C, Bacon R, Dwyer R, Morrison KS, Toohey K, O'Dea A, et al. The Role of Telehealth During the COVID-19 Pandemic Across the Interdisciplinary Cancer Team: Implications for Practice. Semin Oncol Nurs. 2020 Dec;36(6):151090.

Doi: 10.1016/j.soncn.2020.151090

[54] Eldeib HK, Abbassi MM, Hussein MM, Salem SE, Sabry NA. The Effect of Telephone-Based Follow-Up on Adherence, Efficacy, and Toxicity of Oral Capecitabine-Based Chemotherapy. Telemed J E Health. 2019 Jun;25(6):462-70.

Doi: $10.1089 / \mathrm{tmj} .2018 .0077$

[55] Holmström IK, Gustafsson S, Wesström J, Skoglund K. Telephone nurses' use of a decision support system: An observational study. Nurs Health Sci. 2019 Dec;21(4):501-507.

Doi: $10.1111 /$ nhs. 12632

[56] Emfield Rowett K, Christensen D. Oncology Nurse Navigation: Expansion of the Navigator Role Through Telehealth. Clin J Oncol Nurs. 2020 Jun 1;24(3):24-31.

Doi: $10.1188 / 20$. cjon.s1.24-31

[57] Tashkandi E, BaAbdullah M, Zeeneldin A, AlAbdulwahab A, Elemam O, Elsamany S, et al. Optimizing the Communication with Cancer Patients During the COVID-19 Pandemic: Patient Perspectives. Patient Prefer Adherence. 2020 Jul 20;14:1205-12.

Doi: $10.2147 /$ ppa.s263022

[58] Gray DM, Joseph JJ, Olayiwola NJ. Strategies for digital care of vulnerable patients in a COVID-19 world-keeping in touch. JAMA Health Forum. 2020 Jun; 1(6):e200734. 
Doi: $10.1001 /$ jamahealthforum.2020.0734

[59] Riba MB, Donovan KA, Andersen B, Braun I, Breitbart WS, Brewer BW, et al. Distress Management, Version 3.2019, NCCN Clinical Practice Guidelines in Oncology. J Natl Compr Canc Netw. 2019 Oct 1;17(10):1229-49.

Doi:10.6004/jnccn.2019.0048

[60] Klemm P, Bunnell D, Cullen M, Soneji R, Gibbons P, Holecek A. Online cancer support groups: a review of the research literature. Comput Inform Nurs. May-Jun 2003;21(3):136-42.

Doi: $10.1097 / 00024665-200305000-00010$

[61] Bartlett YK, Coulson NS. An investigation into the empowerment effects of using online support groups and how this affects health professional/patient communication. Patient Educ Couns. 2011 Apr;83(1):113-9.

Doi: $10.1016 / j . p e c .2010 .05 .029$

[62] Johansson V, Islind AS, Lindroth T, Angenete E, Gellerstedt M. Online Communities as a Driver for Patient Empowerment: Systematic Review. J Med Internet Res. 2021 Feb 9;23(2):e19910.

Doi: $10.2196 / 19910$

[63] Shankar A, Saini D, Roy S, Mosavi Jarrahi A, Chakraborty A, Bharti SJ, et al. Cancer Care Delivery Challenges Amidst Coronavirus Disease - 19 (COVID-19) Outbreak: Specific Precautions for Cancer Patients and Cancer Care Providers to Prevent Spread. Asian Pac J Cancer Prev. 2020 Mar1;21(3):569-73.

Doi: 10.31557/apjcp.2020.21.3.569

[64] Rohani C, Sedaghati Kesbakhi M, Mohtashami J. Clinical empathy with cancer patients: a content analysis of oncology nurses' perception. Patient Prefer Adherence. 2018 Jun 21;12:1089-98.

Doi: $10.2147 /$ ppa.s156441

[65] Cheshire WP, Barrett KM, Eidelman BH, Mauricio EA, Huang JF, Freeman WD, et al. Patient perception of physician empathy in stroke telemedicine. J Telemed Telecare. 2020 Jan 27:1357633x19899237.

Doi: $10.1177 / 1357633 \times 19899237$

[66] Smaradottir BF, Fensli RW. An Evaluation of Telemedicine Systems in PatientCentred Care Teams. Stud Health Technol Inform. 2020 Jun;271:65-66.

Doi: $10.3233 /$ shti200075

[67] Chaet D, Clearfield R, Sabin JE, Skimming K. Ethical practice in Telehealth and Telemedicine. J Gen Intern Med. 2017 Oct;32(10):1136-40.

Doi: $10.1007 / \mathrm{s} 11606-017-4082-2$

[68] Al-Samarraie H, Ghazal S, Alzahrani AI, Moody L. Telemedicine in Middle Eastern countries: Progress, barriers, and policy recommendations. Int J Med Inform. 2020 Sep;141:104232.

Doi : 10.1016/j.ijmedinf.2020.104232

[69] Teo I, Krishnan A, Lee GL. Psychosocial interventions for advanced cancer patients: A systematic review. Psychooncology. 2019 Jul;28(7):1394-407.

Doi : $\underline{10.1002 / \text { pon. } 5103}$ 